\title{
Near-infrared Laser Energy Transmission through Teeth with Crack Lines: An In-vitro Study
}

\author{
Ashita Sapra \\ Arun Darbar \\ Roy George
}

School of Medicine and Dentistry, Griffith University, Gold Coast, Australia

\section{Background and Objectives}

To evaluate the difference in near-infrared $(810 \mathrm{~nm})$ laser energy transmission through teeth with and without cracks.

\section{Materials and Methods}

Extracted teeth were sectioned and examined visually for the presence of cracks with the aid of photographs and a trans-illuminator. Fourteen sections, each with cracks (Group A) and no cracks (Group B) were identified and placed $15 \mathrm{~mm}$ from the tip of a 300 micron fiber, prior to activation with an $810 \mathrm{~nm}$ diode laser $(0.1 \mathrm{~W}, 50 \mathrm{~ms}$ interval, $100 \mathrm{~ms}$ duration). A power meter positioned behind the tooth recorded the average energy that was transmitted through the samples. Unpaired $t$-test analysis was used to determine if the tooth sections with cracks allowed higher power passage compared to sound teeth.

\section{Results}

The mean power recording for the cracked teeth (Group A) was significantly greater $(p=0.0005)$ than that for the non-cracked teeth (Group B).

\section{Conclusion}

Within the limitations of this study, it is evident that significantly higher laser energy passes through teeth with cracks in comparison to teeth without cracks. A recent clinical study has also shown that lasers could be used to assess symptomatic cracked teeth. Hence, further research is required to determine the relative increase in energy required to identify symptomatic cracked teeth.

\section{Key words}

Cracked teeth; Near-infrared lasers; Endodontics; Diagnosis; Laser transmission 


\section{INTRODUCTION}

Cracks in teeth, are defined as visible fracture lines that are present on the coronal tooth surface. This encompasses three categories; craze lines, fractured cusp and cracked tooth. ' Craze lines are superficial cracks present within enamel that require no treatment. ${ }^{1}$ Fractured cusp and cracked tooth however are deeper crack lines that extend to or beyond the dentinal- enamel junction and result in variable symptoms. ${ }^{1}$ Diagnosis of cracked tooth is difficult as patients symptoms vary depending on the direction and extent of the crack and consequent health of the pulp. ${ }^{2}$

Current diagnostic methods to visualize a crack include, visual inspection, trans-illumination, ultrasound and micro-computer tomography (Micro-CT). ${ }^{3-5}$ However the lack of in-vivo studies, the expense and restricted clinical accessibility, limits the use of ultrasound and micro-CT in dental clinics. ${ }^{6}$ Visual inspection and trans-illumination cannot definitively identify a symptomatic crack (i.e. a fractured cusp or cracked toothl from an asymptomatic crack (i.e. craze lines). ${ }^{7.8}$

Lasers have recently been used for a number of applications in dentistry. ${ }^{9-11}$ The limited absorption of near infra-red lasers (700-1500 nm), allows for better nonablative penetration into tooth structure. ${ }^{11}$ A recent clinical study showed that lasers could be used as an adjunct in location and management of cracked teeth. ${ }^{12}$ The study indicated a near infra-red laser scan of the surface of a tooth with a crack through dentine caused a sharp pain that disappeared immediately following the removal of the stimulus or when the scan was not in the region of the crack. The study also showed good outcome after a follow-up period of 4 years in teeth that were diagnosed and managed. The study proposed that the findings could help with the diagnosis of teeth with symptomatic cracks. Hence further research is required to determine if this relative increase in energy is beneficial in identifying symptomatic cracked teeth.

Currently, no studies have shown the variation of energy transmission in teeth assessed to have a crack and those with non-visible cracks. The purpose of this investigation is to evaluate the laser energy transmission in-vitro of teeth with and without a crack. Understanding near infrared laser energy transmission through teeth with and without cracks could help develop protocols in using this technology to aid in the diagnosis and management of cracked teeth.

\section{MATERIALS AND METHODS}

Extracted teeth were selected, each with or without visible cracks were selected for this study. All teeth were examined with a trans-illuminator using loupes to determine the presence or absence of a crack. All teeth were sectioned mesio-distally, into two halves' using a fine diamond disc (ISO 806104389514 220) and continuous flow of water. Teeth were cleaned gently with an ultrasonic headpiece and then the pulpal surface of each sectioned tooth was flattened with sand paper and water (P800) to a final thickness of 4-5 $\mathrm{mm}$ from the external tooth surface. The thickness of each tooth section was measured with a Dental crown gauge (graduated $0-10 \mathrm{~mm}$ ) with a resolution of $0.1 \mathrm{~mm}$. Teeth sections with thickness less than 4-5 mm were excluded to ensure presence of enamel and dentine. Additional teeth added to the sample to ensure a final sample size of fourteen teeth in each group. The selected tooth sections were then immersed in 15\% ethylenediaminetetraacetic acid (EDTA) (Endosure; Dentalife, Ringwood, VIC, Austrailial solution and 1\% sodium hypochlorite ( $\mathrm{NaOCl}$ (Endosure) for two minutes each to ensure remove smear layer, disinfection and ability to assess the internal tooth surface. To ensure the presence or absence of cracks was not misdiagnosed during the first assessment; all teeth were further photographed with a Canon 500 DSLR camera (shutter speed at 1/13, aperture at F29 and ISO at 800) under trans-illumination and assessed. Two photographs of each section of the teeth were taken under standardized lighting conditions with a macro lens. Photographs of the enamel surface of the teeth were taken with a trans-illuminator facing the dentinal surface. Alternatively photographs of the dentinal surface were taken with the trans-illuminator facing the enamel surface. After exclusion, a total of 14 teeth section each were available for the study of laser energy transmission though enamel and dentine.

\section{Diode laser setup}

A Picasso (810 nm laser; AMD, Santa Clara, UT, USA) laser with a 300-micron fiber tip was used for this study. The power meter sensor (Thor Labs S121C, 400-1100 $\mathrm{nm}$ ) was connected to a power meter (PM200, ThorLabs, Newton, NJ, USA). Each tooth section with the identified treatment area was carefully positioned directly over the power meter sensor, with Blu-Tack (Bostik, Brisbane, QLD, Austrailial placed over the occlusal surface to stabilise the tooth section, attaching the tooth flat on the power sensor. Tooth sections that did not completely cover the sensor were also excluded. The $810 \mathrm{~nm}$ laser beam was 
activated with a foot peddle, using a 300-micron fiber tip at $0.1 \mathrm{~W}$ at $50 \mathrm{~ms}$ interval for $100 \mathrm{~ms}$ duration. The distance between the tooth and the end of the tip was kept constant at $15 \mathrm{~mm}$. The beam was aimed at the crack line or center of the tooth, in Group A and B respectively and the reading on the power meter was recorded. This was repeated three times for each tooth fragment.

Control measurements were also recorded measuring the power meter reading without the laser and without the tooth positioned over the sensor. The reading of the sensor with laser beam but no tooth and alternatively with tooth but no laser beam was also recorded.

\section{Data analysis}

An unpaired $t$-test was conducted to determine if the power detected through cracked tooth sections was significantly higher than the power detected through noncracked tooth sections.

\section{RESULTS}

Fourteen tooth sections with cracks and further fourteen tooth sections without cracks were detected. Control

Table 1. Data showing mean and standard deviation of cracked vs. non-cracked teeth

\begin{tabular}{lc}
\hline \multicolumn{1}{c}{ Group } & Power $(\mathrm{mW}) /$ standard deviation \\
\hline Control: no tooth, with laser & $29.96 / 0.00$ \\
Group A: cracked tooth & $0.59 / 0.23$ \\
Group B: non-cracked tooth & $0.32 / 0.11$ \\
\hline
\end{tabular}

tests were conducted to calibrate power meter readings (Table 1). Tooth was not positioned on the filter and laser was not activated, the power meter detected $0.16 \mathrm{~mW}$ power, energy detected from the natural environment. However, if the $810 \mathrm{~nm}$ diode laser beam was activated, $29.96 \mathrm{~mW}$ of power was detected. After positioning a tooth section and no laser fired the power meter detected a reading of $0.01 \mathrm{~mW}$. The tooth prevented the natural energy from being detected by the sensor. Hence, when the $810 \mathrm{~nm}$ diode laser was activated, the energy emitted from the laser, propagating through the tooth, was the energy detected by the power meter sensor.

Fourteen tooth sections with cracks were identified and the average power meter readings for each tooth were recorded. Photographic records with the use of transilluminator aided visual detection of the presence of a crack (Fig. 1A, B). The power meter reading ranged from $0.23 \mathrm{~mW}$ to $0.92 \mathrm{~mW}$. The mean power meter reading, for teeth with cracks along the enamel surface, was 0.59 $\mathrm{mW}$.

Fourteen tooth sections with no cracks evident on the enamel surface were identified and classified into Group $B$. Photographic record with the aid of trans-illuminator (Fig. 1C, D) confirmed the absence of visual crack within the tooth. The averages of the three power meter recordings of each tooth were identified. The range of the power meter reading was between $0.13 \mathrm{~mW}$ and $0.50 \mathrm{~mW}$. The mean power meter reading of the fourteen tooth sections was $0.37 \mathrm{~mW}$. This is significantly lower ( $p$-value $=0.0005$ ) than the mean power detected through cracked teeth (Group A mean = $0.59 \mathrm{~mW}$ ).
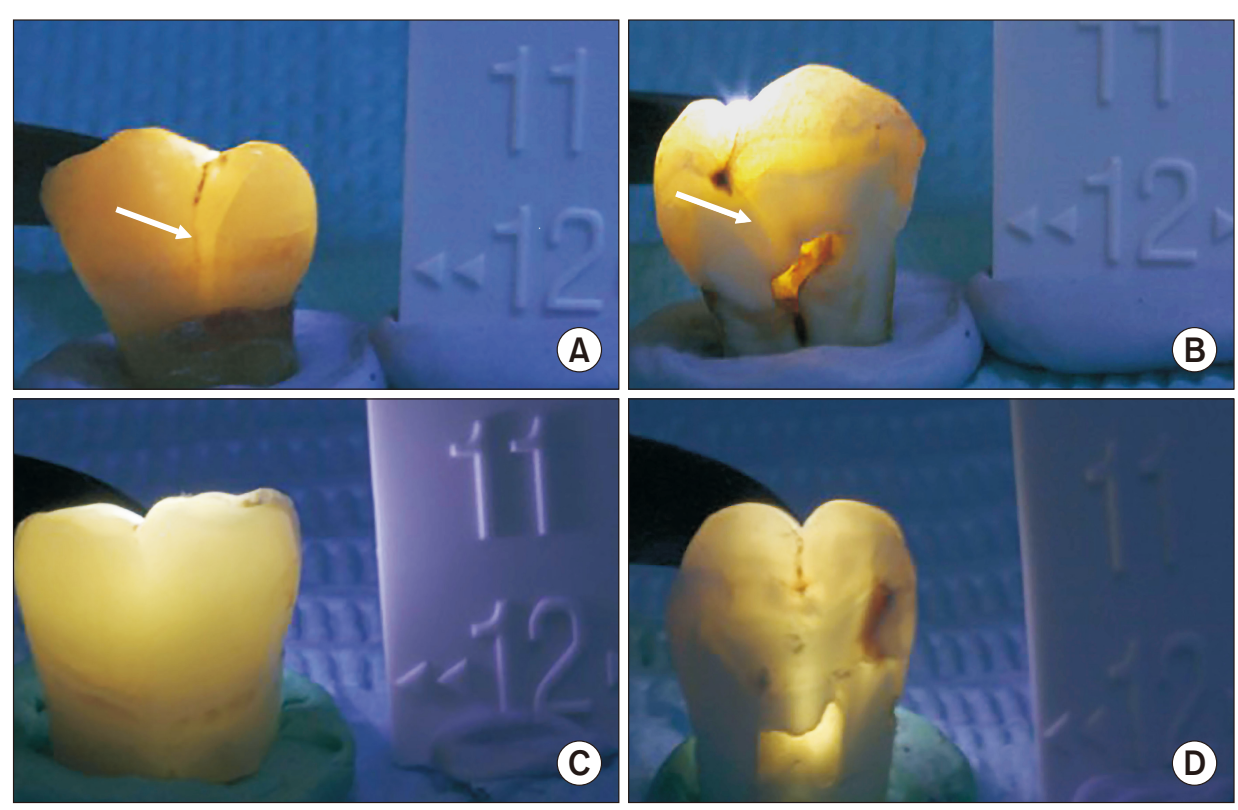

Fig. 1. Enamel and dentinal surface of trans-illuminated tooth sections. (A) Crack (arrow) evident on the buccal enamel surface and (B) possible crack on the dentinal surface. (C) No crack lines evident on the enamel surface and (D) no crack lines evident on the dentinal surface. 


\section{DISCUSSION}

Cracked teeth are difficult to diagnose, as symptoms vary depending on the depth of the crack and subsequent health of the pulp. ${ }^{2}$ Not all cracks, visible with or without a trans-illuminator, are symptomatic and require treatment. 'While bite test, is highly diagnostic, it fails to identify the exact location and path of the symptomatic crack. ${ }^{13}$ Furthermore, Sun et al. (2014) identified the success of laser ultrasonic system in determining the location and depth of stimulated planar cracks in extracted teeth. ${ }^{14}$ However their efficacy in identifying natural geometrically complex cracks remains uncertain. ${ }^{4,14}$ Micro Computed Tomography is also successful in detecting dentinal cracks in extracted teeth. ${ }^{5,15}$ However, the lack of accessibility, increased cost of use and high radiation dose remains a limitation to its everyday clinical application. ${ }^{6}$ Near infrared diode lasers have a number of other clinical applications le.g. gingivectomy, frenectomy, haemorragic lesion removal, tooth whitening, analgesia, etc.). ${ }^{16-18}$ The ability to use these lasers for detection of cracks could add to its value to dental practitioners.

Laser wavelength, power and mode of operation affect the way the laser interacts with the tooth. ${ }^{19}$ Near infra-red lasers (700-1500 nm), allow for better non-ablative penetration into tooth structure. ${ }^{11}$ The purpose of this in vitro study was to determine the difference in power transmission through cracked and non-cracked tooth sections, rather than the actual value of power measured. Hence, due to the high sensitivity level of the power meter, measuring energy in milli-Watts, the lowest energy setting was selected at $0.1 \mathrm{~W}$ energy at $50 \mathrm{~ms}$ intervals for $100 \mathrm{~ms}$ duration. These settings would not harm the hard tissue and were also detected by the power meter.

Laser waves interact with hard surface of teeth through a combination of processes. This may include reflection, scattering, transmission and absorption of laser energy. ${ }^{19}$ Near infrared lasers, in the wavelength range 810-980 $\mathrm{nm}$ have low absorption coefficients of water and hydroxyapatite. ${ }^{20}$ Majority of energy is transmitted through to the pulp rather than dissipating at the tooth surface. ${ }^{20}$ This allows scattering and diffusion of energy through the dentinal tubules. ${ }^{20}$ Gutknecht et al. (2000) recorded 74\% bacterial reduction at $500 \mu \mathrm{m}$ thick dentine slice, hence illustrating the penetration power of $810 \mathrm{~nm}$ diode laser. ${ }^{21}$ Hence, transmission capability of $810 \mathrm{~nm}$ diode laser can be compared through cracked and non-cracked sections. This study showed that there was significantly ( $p=0.0005$ ) larger transmission of laser energy through cracked in comparison to non-cracked teeth. This could be a result of cracks collimating energy, like optical fibers, through the dentinal crack to the pulpal tissue. Craze lines or noncracked teeth are unlikely to allow a similar passage of energy as fractured cusp and cracked tooth. This may explain the larger power transmission difference through cracked tooth sections over non-cracked tooth sections.

Clinically there is a discrepancy in the literature, in distinguishing craze lines and dentinal cracks. Rivera and Walton (2008) stated trans-illumination distinguishes craze lines from fractured teeth, as craze lines allow light to pass through the crack and illuminate the whole tooth. ${ }^{1}$ More recently, Mathew et al. (2012) stated trans-illumination dramatizes craze lines as structural cracks. ${ }^{8}$ Hence as there is no visually accurate method to distinguish between the two groups, any teeth with visual cracks on trans-illumination were classified in Group $A$ and teeth with no cracks in Group B. Craze lines are cracks within enamel that are asymptomatic and require no treatment. ${ }^{1}$ However it is evident lasers can identify symptomatic cracks from non symptomatic cracks. ${ }^{12}$ This could be due to the larger transmission of energy through structural cracks. However further in-vivo research with more participants is required.

Various experimental approaches were taken to increase validity and reliability of the data collected. To assist in the visual presence of complete cracks, photographs of the enamel and dentinal surface of the tooth with a trans-illuminator were recorded. Hence confirming tooth sections were classified into their appropriate group and to minimize human error. Measuring the power meter reading for each tooth three times, increased reliability and validity of the results. A ruler measured the distance between the tooth sample and microfiber tip to be a constant $15 \mathrm{~mm}$. This ensured that the amount of energy that dissipated through the environment also remained constant.

Exclusion criteria of samples encompassed the presence of any restorative material and tooth thickness measuring less than four millimeters. The thickness of the sample was maintained between four to five millimeters, as teeth with increased thickness would allow less energy to pass, as it would dissipate though the tooth. Similarly, thin samples were also excluded, as they would result in an increased power meter reading irrespective of the presence or absence of a crack. Teeth with restorations were also excluded as amalgam, composite and glass ionomer cement restorations may alter the transmission of energy through the tooth. ${ }^{22}$ Kilinc et al. (2012) has reported surface alterations of filling materials that have been irradiated with $810 \mathrm{~nm}$ diode laser. ${ }^{23}$ Energy 
could be dissipated or restorations may result in higher energy transmission due to reduced tooth thickness. Hence to control variation in results due to the presence of a restorative material, samples with fillings were also excluded. As Ratcliff et al. (2001) identified that the risk of crack formation increased by twenty-nine times with the presence of a restoration. ${ }^{24}$ Further investigation is warranted to determine if there is a difference in the reading with the presence of various restorative materials, such as composite, amalgam or glass ionomer restorations.

Further in-vitro research is required to compare the difference in power transmission at different power settings, interval levels and alternative low-level laser wavelengths between cracked and non-cracked tooth sections. These factors could help determine the relative increase in energy needed to identify symptomatic cracked teeth. Transmission studies also provide us with an understanding of dose when managing teeth with photobiomodulation.

\section{CONCLUSION}

Within the limitations of this in vitro study, the $810 \mathrm{~nm}$ diode laser energy passing through a tooth with cracks is statistically significantly higher ( $p=0.0005$ ) than a visually sound tooth. This difference in power may be due to higher energy transmission through craze lines, fractured cusp or cracked tooth. However, further in-vivo research, with a larger participant size, is required to determine the effect of the energy difference on the vital pulp.

\section{CONFLICT OF INTEREST}

No potential conflict of interest relevant to this article was reported.

\section{FUNDING}

None.

\section{ORCID}

Ashita Sapra, https://orcid.org/0000-0001-7430-7820 Arun Darbar, https://orcid.org/0000-0002-1548-7590 Roy George, https://orcid.org/0000-0001-7876-1334

\section{REFERENCES}

1. Rivera E, Walton RE. Endodontics: colleagues for excellence newsletter. Cracking the cracked tooth code: detection and treatment of various longitudinal tooth fractures. Chicago: American Association of Endodontists; 2008.

2. Kahler W. The cracked tooth conundrum: terminology, classification, diagnosis, and management. Am J Dent 2008;21:27582.

3. Albers HF. Tooth colored restoratives: principles \& techniques. Shelton: People's Medical Publishing House USA Ltd.; 2002. p.302.

4. Culjat MO, Singh RS, Brown ER, Neurgaonkar RR, Yoon DC, White SN. Ultrasound crack detection in a simulated human tooth. Dentomaxillofac Radiol 2005;34:80-5.

5. Pop I, Manoharan A, Zanini F, Tromba G, Patel S, Foschi F. Synchrotron light-based $\mu \mathrm{CT}$ to analyse the presence of dentinal microcracks post-rotary and reciprocating NiTi instrumentation. Clin Oral Investig 2015;19:11-6.

6. Patel S, Dawood A, Ford TP, Whaites E. The potential applications of cone beam computed tomography in the management of endodontic problems. Int Endod J 2007;40:818-30.

7. Alassaad SS. Incomplete cusp fractures: early diagnosis and communication with patients using fiber-optic transillumination and intraoral photography. Gen Dent 2011;59:132-5.

8. Mathew S, Thangavel B, Mathew CA, Kailasam S, Kumaravadivel K, Das A. Diagnosis of cracked tooth syndrome. J Pharm Bioallied Sci 2012;4(Suppl 2):S242-4

9. Shakibaie F, George R, Walsh LJ. Applications of laser induced fluorescence in dentistry. Int J Dent Clin 2011;3:38-44.

10. George R. Laser in dentistry- review. Int J Dent Clin 2009:1:139.

11. Walsh LJ. The current status of laser applications in dentistry. Aust Dent J 2003;48:146-55; quiz 198.

12. Sapra A, Darbar A, George R. Laser-assisted diagnosis of symptomatic cracks in teeth with cracked tooth: a 4-year invivo follow-up study. Aust Endod J 2020;46:197-203.

13. Seo DG, Yi YA, Shin SJ, Park JW. Analysis of factors associated with cracked teeth. J Endod 2012;38:288-92.

14. Sun K, Yuan L, Shen Z, Xu Z, Zhu Q, Ni X, et al. Scanning laserline source technique for nondestructive evaluation of cracks in human teeth. Appl Opt 2014;53:2366-74

15. Landrigan MD, Flatley JC, Turnbull TL, Kruzic JJ, Ferracane JL, Hilton TJ, et al. Detection of dentinal cracks using contrast-enhanced micro-computed tomography. J Mech Behav Biomed Mater 2010;3:223-7.

16. Trost $L$, Kaiser K. Emerging applications for the soft-tissue diode laser. Nashville: Endeavor Business Media, LLC.; 2009.

17. Klunboot U, Arayathanitkul K, Chitaree R, Emarat N. The temperature effects of diode laser on pulpal tissues for the teeth whitening treatment. Proced Eng 2012;32:722-6.

18. Artés-Ribas M, Arnabat-Dominguez J, Puigdollers A. Analgesic effect of a low-level laser therapy $(830 \mathrm{~nm})$ in early orthodontic treatment. Lasers Med Sci 2013;28:335-41. 
19. De Moor RJ, Verheyen J, Diachuk A, Verheyen P, Meire MA, De Coster PJ, et al. Insight in the chemistry of laser-activated dental bleaching. ScientificWorld Journal 2015;2015:650492.

20. Viapiana R, Sousa-Neto MD, Souza-Gabriel AE, Alfredo E, Silva-Sousa YT. Microhardness of radicular dentin treated with 980-nm diode laser and different irrigant solutions. Photomed Laser Surg 2012;30:102-6.

21. Gutknecht N, van Gogswaardt D, Conrads G, Apel C, Schubert C, Lampert F. Diode laser radiation and its bactericidal effect in root canal wall dentin. J Clin Laser Med Surg 2000;18:57-60.

22. Kilinc E, Drukteinis S, Roshkind DM, Hardigan PC. Thermal absorption of CO2, Nd:YAG, diode lasers in dental materials. In: International Association of Dental Research (IADR) 89th Gen- eral Session and Exhibition; 2011 Mar 14-19; San Diego. 2011.

23. Kilinc E, Rothrock J, Migliorati E, Drukteinis S, Roshkind DM, Bradley P. Potential surface alteration effects of laser-assisted periodontal surgery on existing dental restorations. Quintessence Int 2012;43:387-95.

24. Ratcliff S, Becker IM, Quinn L. Type and incidence of cracks in posterior teeth. J Prosthet Dent 2001;86:168-72.

How to cite this article: Sapra A, Darbar A, George R. Nearinfrared laser energy transmission through teeth with crack lines: an in-vitro study. Med Lasers 2021;10:214-219. https://doi.org/10.25289/ML.2021.10.4.214 